\title{
Finite Element Analysis on Tensile Stiffness of Cold-Formed Steel Bolted Connections
}

\author{
Bo Cheng ${ }^{*}$ and Zhenyu $\mathrm{Wu}$
}

\author{
School of Civil Engineering, Harbin Institute of Technology, Harbin, 150090, P.R. China
}

\begin{abstract}
This paper presents a finite element analysis on the tensile stiffness of steel bolted connections which are fabricated from thin-walled cold-formed steel strips and their members. This type of bolted connection is usually used to assemble the diagonal bracing member in the light steel structure. Unlike the architectural steel structure, thin walled steel bolted connection cannot be simplified into a hinge joint due to the weak tensile stiffness of connection. The calculation of tensile stiffness of bolted connection is necessary to accurately evaluate the effectiveness of bracing system in the coldformed steel structure. Based on the existing test results and analysis results, finite element (FE) models with threedimensional solid elements were established to investigate the tensile stiffness of bolted connections between cold-formed steel plates under shear. The analysis with non-linear material and contact elements was carried out in order to predict the load-displacement relationships of bolted connections. Furthermore, a parametric study on single-bolted or two-bolted connections with different configurations was performed to study the relationship of connection tensile stiffness and structural parameters such as bolt diameter, plate thickness and steel yield strength. According to the stiffness results obtained from parametric study, six calculating equations for practical design of cold-formed steel bolted connection have been proposed. The calculation results of the stiffness equations are in a good correlation with those of FE analysis, and the proposed equations have been found to provide estimates of tensile stiffness of bolted connections with reasonable accuracy.
\end{abstract}

Keywords: Bolted connection, cold-formed steel, tensile stiffness, finite element analysis, calculating equation, parametric study.

\section{INTRODUCTION}

Cold-formed steel sections are found in various civil constructions, ranging from purlins and girts, to steel framings and pillars. The advantages of using cold-formed steel sections are derived from their low cost together with high yield strength and good versatility. In residential structure system, hot-rolled steel sections are commonly used as major force-bearing components while cold-formed steel sections are used as subordinate components to support light wall board and interior decoration element. However, in some commercial structure system, all the structure members are made of cold-formed steel profiles. For the simple and convenient assembly, some cold-formed profiles are assembled together by steel bolts. Fig. (1) shows two types of bolted connections in storage pallet rack systems which are an important structure mode of cold-formed sections.

$\mathrm{C}$ and $\mathrm{Z}$ sections with different edge lips and internal stiffeners are the most common cold-formed steel sections, and the thickness of steel plates of these sections typically ranges from $1.2 \mathrm{~mm}$ to $3.0 \mathrm{~mm}$. The steel yield strength of cold-formed sections which is commonly used ranges from $280 \mathrm{~N} / \mathrm{mm}^{2}$ to $450 \mathrm{~N} / \mathrm{mm}^{2}$. In recent years, due to advances in steel industry, cold-formed steel strips with high yield strength of $550 \mathrm{~N} / \mathrm{mm}^{2}$ are also available for building products.

*Address correspondence to this author at the School of Civil Engineering, Harbin Institute of Technology, Harbin, Heilongjiang, 150090, P.R. China: E-mail: chengbo198508@126.com

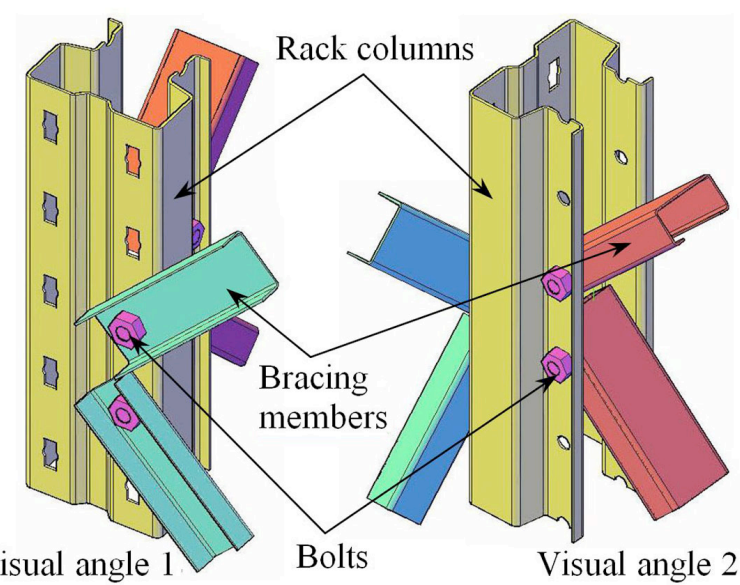

Fig. (1). Bolted connections in storage pallet rack structure.

Nowadays, in the design specifications [1-3] of coldformed steel structure, the provisions on cold-formed steel connections involve the load-carrying capacities and construction requirements of bolted connections. Moreover, the objectives of research work [4-7] on cold-formed steel bolted connections were to obtain a more comprehensive understanding of bearing failure mode and bearing resistance of this type of bolted connection. The stress-strain behavior of stainless steel, which has the steadily growing popularity, is different from that of common carbon steel. Some previous studies [8-11] focused on the structural behavior of bolted connections made of cold-formed stainless steel. 
The connection between cold-formed steel sections comprising a few bolts cannot be simplified into the simple hinge joint due to the lack of rigidity. In some architectural steel structure, diagonal bracing members are connected to the steel frames in complicated ways to ensure the bearing capacity and stiffness of connections. However, for the simple assembly, the cold-formed steel bracing members are installed directly on the structural frames through several bolts, resulting in the weak tensile connection which can seriously weaken the support effect of diagonal bracing member. In the sections below, this weakened effect is also evaluated in quantitative analysis. Unlike the load-carrying capacity of bolted connection, the tensile stiffness of this type of bolted connection has not received much attention. Furthermore, it should be noted that due to the greater slenderness ratio of cold-formed bracing members, the bracing members cannot withstand the pressure and can only provide support against tension in practice.

Finite element method has become more and more popular in almost all research fields, especially the civil engineering. Therefore, in order to investigate the tensile stiffness of thin-walled steel bolted connections, in this study, finite element (FE) models were established on the basis of the performance curves of the connection specimens in references. For single-shear bolted connections studied in the paper, only single plate with free edges was modeled. Parametric studies with different structural parameters such as blot diameter, plate thickness and steel yield strength were conducted in order to investigate the relationship of these parameters and tensile stiffness of bolted connections. The main objective of this paper is to establish the calculating formula of connection tensile stiffness in order to assist the design engineer in the designing of diagonal bracing members.

\section{REFERENCE TEST RESULTS AND ANALYSIS RESULTS}

In recent years, some experimental researches and finite element analyses on cold-formed stainless steel bolted connections have been carried out. The load-displacement curves for stainless steel bolted connections in references [8, 11] are available and chosen to validate the reliability of finite element models which are established in the paper. The major difference between cold-formed stainless steel and normal steel which is studied in this paper is their mechanical properties. By considering different material properties of steel, the finite element method which is compared with existing research data of stainless steel bolted connection can also estimate the static performance of normal steel bolted connection with reasonable accuracy, especially for calculating the tensile stiffness of connections. In the calculation of tensile stiffness, the connection deformations in the form of axial extensions are not large.

Fig. (2) shows the single shear connection specimens in reference [11], which have three different configurations of bolt number and bolt arrangement. The speciality of these bolted connections is the use of lips of nominal $10 \mathrm{~mm}$ height to prevent the out-of-plane curling deformation at the overlapped connection region. The type of connection can accurately represent the true behavior of profiled structural members, for example channel sections which are more frequently used than flat strips in cold-formed steel structure. In Fig. (2), the first letter "A" and "T" in the specimen labels indicate the two types of stainless steel material, EN1.4301 and EN1.4571 [11] respectively. The nominal thickness of steel plate is $1.5 \mathrm{~mm}$. The bolts assembled in the connection specimens are tightened to a torque of approximately 10 N.m, which allowed the bolt slip at a small load level. The experimental load-displacement relationships of six bolt connections are given in Fig. (3). Because the bolt slip is expected at a small load level, the slip displacement is shifted in all the test curves.

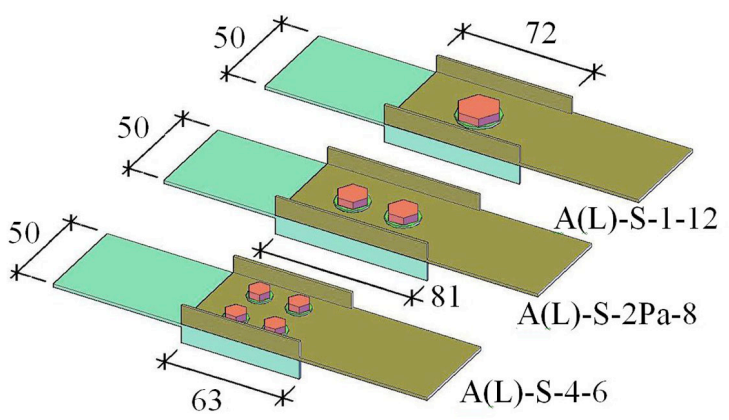

Fig. (2). Configuration of connection specimens in reference [11].

Fig. (4) shows the single shear connection specimens in reference [8], which have two different configurations of bolt arrangement. The speciality of these bolt connections is that the single-shear connections include two types of plates: the cold-formed stainless steel plate $(3.0 \mathrm{~mm}$ thick) and the rigid steel plate $(6.0 \mathrm{~mm}$ thick) whose deformation is very small. The nominal bolt diameter of bolts in connections is $12 \mathrm{~mm}$. The difference of two specimens SC2-3 and SC2-4 is the different end distance $(30 \mathrm{~mm}$ and $60 \mathrm{~mm})$ from the center of a bolt hole to the adjacent end of steel strip in the direction of load. The load-displacement relationships of two types of bolted connections are given in Fig. (5). It should be noted that these curves are not the test data, and they are obtained from the finite element analysis using the FE package ABAQUS in reference [8]. The finite element models in reference [8] also do not consider the slip and pretension of bolts in the connection.

\section{FINITE ELEMENT MODELING}

In the paper, the finite element software ANSYS is used to simulate the experimental behavior of bolted connection. The steel plate, bolt shank and base plate are modeled using the solid element SOLID45, which is an 8-node element with three degrees of freedom at each node.

The main objective of finite element analysis is not always to simulate reality as accurately as possible, but to find the simple model which can provide a sufficiently accurate description of reality. In order to achieve this objective, finite element modeling adopts some simplified methods which are described in detail below. The configurations of finite element models of connection specimens in references $[8,11]$ are shown in Fig. (6).

For the purpose of reducing the model size and computational cost, only one half of one stainless steel plate in the connection is modeled by applying appropriate boundary conditions. The connection specimens in reference 
[11] (Fig. 2) consist of two same steel plates. In the case that the bolt deformation and the friction between two plates are ignored, the load-bearing capacity of the FE model with single plate is the same as that of the tested connection, but the displacement (also named the elongation) of the FE model of connections is about one half of that of the tested connections. The connection specimens in reference [8] (Fig. 4) consist of one cold-formed steel plate and one thick steel plate. Because the deformation of thick plate is very small, only one thinner plate in single shear connections is modeled in order to curtail the run time by reducing the total number of elements as displayed in Fig. (6b).

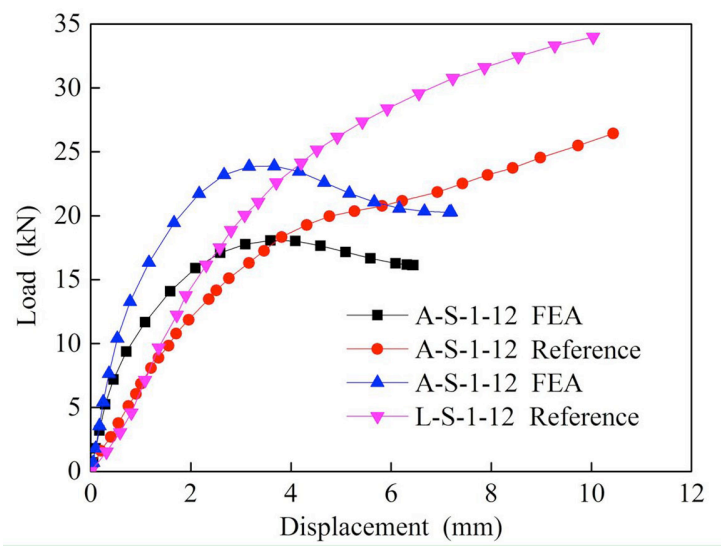

(a)

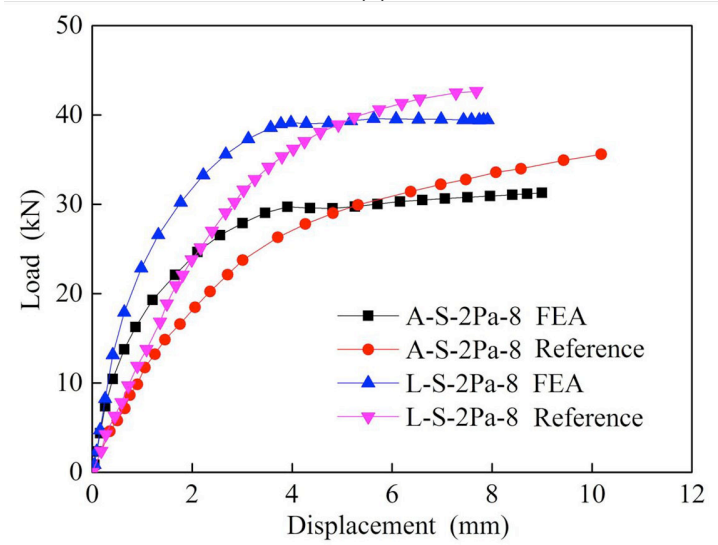

(b)

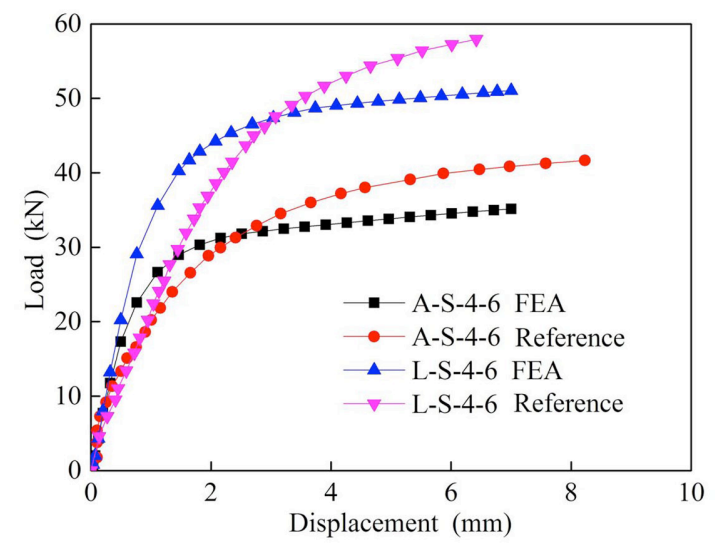

(c)

Fig. (3). Comparison of load-displacement relationships of connection specimens in reference [11].

For the need of calculation accuracy and time saving, the plate is divided into two mesh areas. One part is around bolt holes, and the maximum mesh size of solid element is about $0.75 \mathrm{~mm}$ to $1.0 \mathrm{~mm}$. The other part is not in the vicinity of the bolt holes, and the maximum mesh size of solid element is about $2.0 \mathrm{~mm}$ to $4.0 \mathrm{~mm}$. For the ease of meshing, an artificial small hole of $2 \mathrm{~mm}$ diameter is provided through the centerline of bolt component. The sides of bolt shank and bolt hole are simulated as bearing contact area in finite element model. Contact between the bolt shank and bolt hole is defined using the surface-to-surface contact elements TARGE170 and CONTA174. As shown in Fig. (6), in order to restrain the displacement of steel plate in the negative direction of plate thickness $\left(-u_{2}\right)$, small base plates are set around the bolt hole. Contact between the steel plate and base plate is also defined using the contact elements TARGE170 and CONTA174. No friction effects are taken into account in the contact surface between the steel strip and base plate. The direct bearing between bolt shank and bolt hole is the primary means of load transfer in the connection.

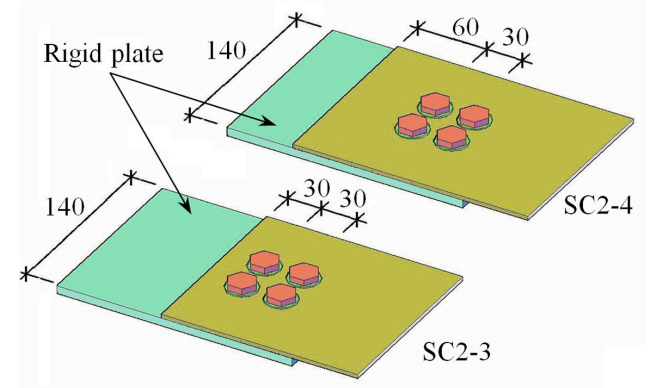

Fig. (4). Configuration of connection specimens in reference [8].

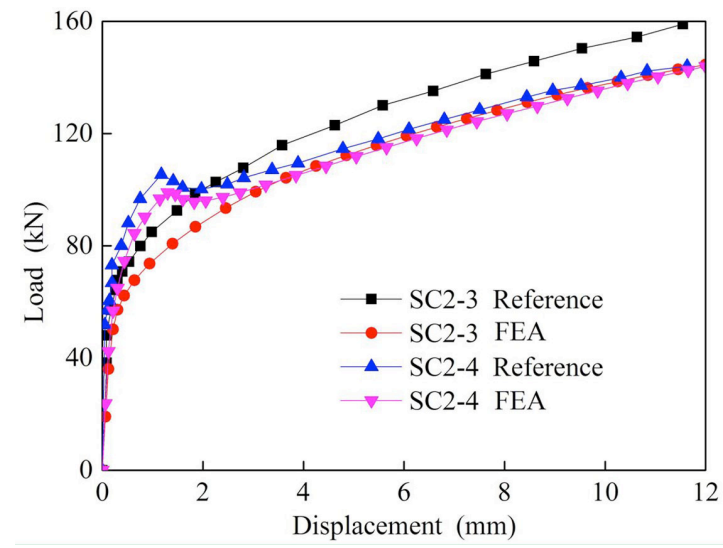

Fig. (5). Comparison of load-displacement relationships of connection specimens in reference [8].

Fig. (6) also illustrates the boundary and loading conditions used in the FE models. Owing to the effect of the actual bolt head, the circular ring of bolt hole (area 1 in Fig. 6) is fixed in the plate thickness direction, the displacement $u_{2}$ of nodes around the bolt hole is zero. The nodes in the symmetry plane (area 2 in Fig. 6) are fixed with symmetric geometric boundary conditions $\left(u_{1}=0\right)$. For the nodes in the lower surfaces of bolt shank and base plate, the degree of freedom is zero: $u_{1}, u_{2}, u_{3}=0$. To simulate the real loading condition, the external force is applied directly on the loading end of the steel strip (Fig. 6) in the negative direction of strip length $\left(-u_{3}\right)$. Loading force is applied at the end of the plate (loading end) by means of uniform displacementcontrol. The nodes around the loading end are fixed in two directions of cross section: $u_{1}, u_{2}=0$. 


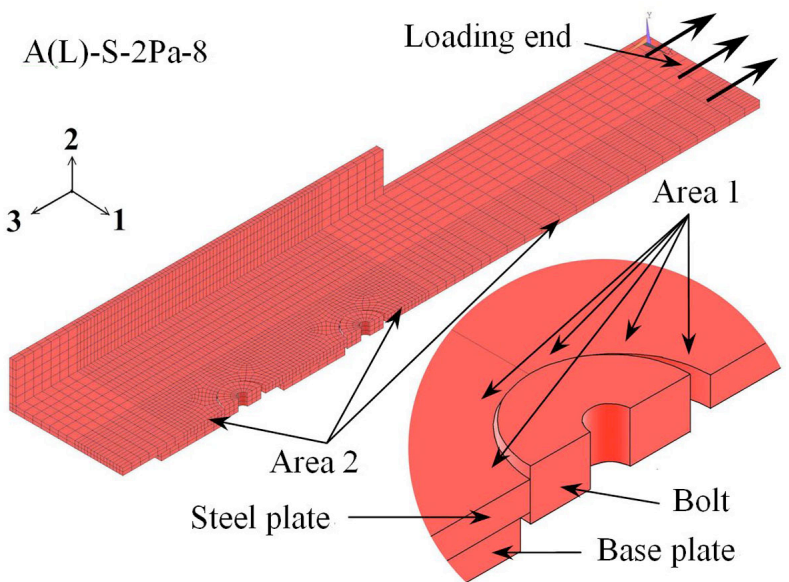

(a) $\mathrm{A}(\mathrm{L})-\mathrm{S}-2 \mathrm{~Pa}-8$

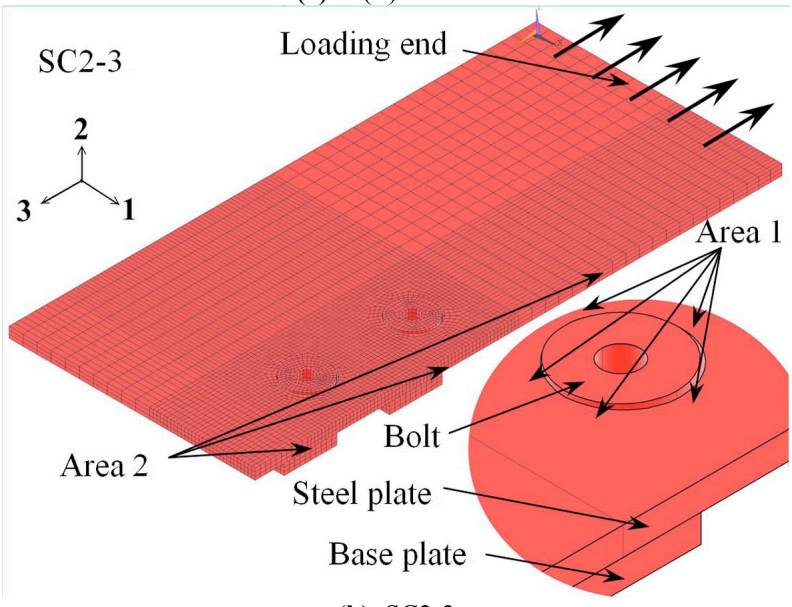

(b) $\mathrm{SC} 2-3$

Fig. (6). FE models of connection specimens in references.

According to the measured material properties and stressstrain curves of thin-walled stainless steel in coupon tests in the reference [8], the material behavior of steel plate for FE models is described [8] approximately by a bilinear stressstrain curve in this study. The first part of the bilinear curve represents the elastic part up to the proportional limit stress (yield strength $f_{\mathrm{y}}$ ) measured elastic modulus $E$. At the yield stress $f_{\mathrm{y}}$, the bilinear curve is turned along the second part whose tangent modulus is $1 \%$ of the elastic modulus $E$. Von Mises yield criteria and isotropic hardening rule are adopted for the material non-linearity. In this paper, the material modeling of FE models [11] is set to the same modeling of FE models [8] described before. All the material properties of steel strip, such as yield stress and elastic modulus, can be found in the two references. The bolt shank and base plate are modeled as the pure elastic material.

Fig. (7) shows the typical deformation shape of test specimens $\mathrm{A}(\mathrm{L})-\mathrm{S}-2 \mathrm{~Pa}-8$ in finite element analysis. The bolt hole becomes enlarged in the load direction because of the shearing action of bolt bar, and the deformation of bolt hole which is closer to the loading end is larger. The portion of steel plate around the bolt holes generates the distinct curling deformation.

The comparisons of load-displacement relationships between reference data and finite element analysis are shown in Fig. (3) and Fig. (5). As shown in Fig. (3), the slope of FE analysis curves is larger than that of test curves at the beginning stage of loading. As the displacement of steel plate increases, the load of FE model increases less quickly than that of test connections. After a certain displacement (ranging from $2 \mathrm{~mm}$ to $5 \mathrm{~mm}$ ), the loads of FE models become less than that of experimental curves. As the loaddisplacement relationships of bolted connections in reference [8] are also obtained from the numeric calculation, a better agreement is found between the curves of different FE models in reference and this paper as illustrated in Fig. (5).

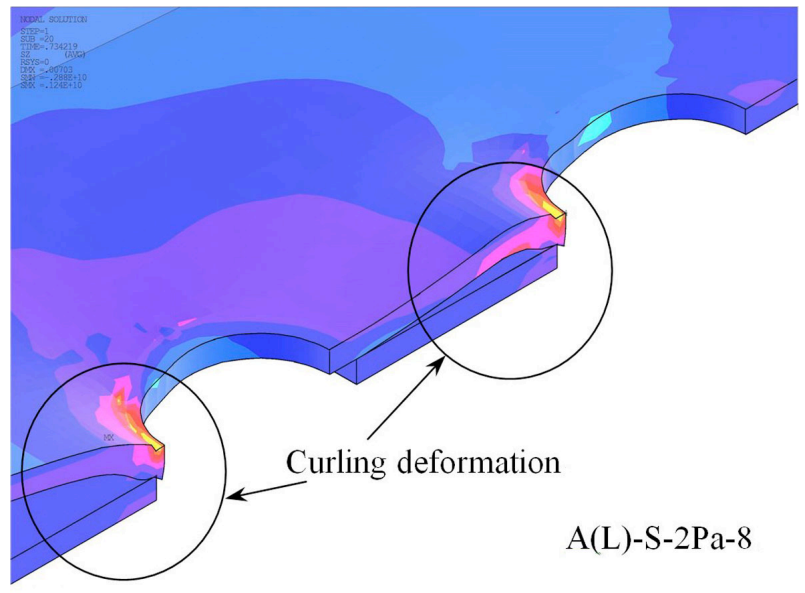

Fig. (7). Typical deformation shapes of specimens in FE analysis.

In the connection models (Fig. (6a) [11], the bolt bar contacts with bolt hole directly and perfectly, regardless of the geometrical imperfections, such as gaps between bolt bar and bolt hole, screw thread of bolt and rough edge of bolt hole. Furthermore, the simplified bilinear stress-strain curve does not consider the strength degradation of steel at large strain. These treatments are the main reasons for larger stiffness of numerical connection model during the initiation of loading. As the displacement of bolted connection becomes larger, the curling deformation occurs in the steel plate, which can restrain the increase of the load carried by bolted connection.

As shown in Fig. (3) and Fig. (5), the load-displacement curves are seriously non-linear, even for the initial part of the curves. The secant stiffness (labeled $K_{\mathrm{XR}}$ or $K_{\mathrm{XF}}$ ), which is the slope of a secant line drawn from the origin point through the selected point that is obtained from the loaddisplacement curves in Fig. (3) or Fig. (5), is used to evaluate the tensile stiffness of bolted connections. For the secant stiffness labels, " $X$ " refers to the displacement of the selected point, while " $R$ " and "F" indicate the reference data and finite element analysis respectively. The secant stiffness comparison results of bolted connections for references and FE analysis in the study are listed in Table $\mathbf{1}$.

For different bolted connection specimens, their curve characteristics are different, thus the displacements of selected points which are taken from the approximate straight segment in load-displacement curves are different. There are two displacements for the selected point of each secant stiffness in Table 1. For the specimens A(T)-S-1-12 and $\mathrm{A}(\mathrm{T})-\mathrm{S}-2 \mathrm{pa}-8$, two displacements of selected points are $1.2 \mathrm{~mm}$ and $2.4 \mathrm{~mm}$. For the specimens A(T)-S-4-6, two displacements of selected points are $0.6 \mathrm{~mm}$ and $1.2 \mathrm{~mm}$. For the specimens SC2-3(4), two displacements of selected points are $0.2 \mathrm{~mm}$ and $0.4 \mathrm{~mm}$. The approximate straight segments in the load-displacement relationships of specimens SC2-3(4) have the lowest displacement values. 
As mentioned before, for bolted connection specimens (SC2-3 and SC2-4) in reference [8], the load-displacement curves are also obtained from the numerical study, thus the differences of connection secant stiffness between the reference [8] and FE analysis in this study are small.

For the bolted connection specimens [11], the loaddisplacement curves are obtained from the experimental study. The secant stiffness from the FE analysis in this study is larger than that of the test results by $22 \%$ to $97 \%$. For the same specimen, as the displacement of the selected point increases, the difference of secant stiffness between the test data and FE model becomes small. For instance, the value of $K_{1.2 \mathrm{~F}} / K_{1.2 \mathrm{R}}$ of specimen A-S-1-12 is 1.50 , but the value of $K_{2.4 \mathrm{~F}} / K_{2.4 \mathrm{R}}$ of specimen A-S-1-12 is 1.22 . The secant stiffness from $\mathrm{FE}$ analysis can be seen as the upper limit of the tensile stiffness of bolted connection with the same configuration.

As mentioned earlier, the tensile stiffness of bolted connection has a great effect on the effectiveness of bracing system in cold-formed structure. It is shown that, the section area $\left(A_{0}\right)$ of thin-walled strips in bolted connections is about $100 \mathrm{~mm}^{2}$ [11]. The length $\left(l_{0}\right)$ of bracing member is supposed to be $2 \mathrm{~m}$. The tensile stiffness $\left(K_{\mathrm{M}}=E A_{0} / l_{0}\right)$ of bracing members in the axial direction is $10 \mathrm{kN} / \mathrm{mm}$. Fig. (8). illustrates the stiffness analysis of diagonal bracing system. In Table 1, the range of tensile stiffness $\left(K_{\mathrm{R}}\right)$ of bolted connections at two ends of bracing member is 5.71 $\mathrm{kN} / \mathrm{mm}$ to $25.13 \mathrm{kN} / \mathrm{mm}$. Compared with the bracing member axial stiffness $\left(K_{\mathrm{M}}=10 \mathrm{kN} / \mathrm{mm}\right)$, the tensile stiffness of bolted connection should not be eliminated. Furthermore, neglecting the tensile stiffness of bolted connection (bracing connection) is inappropriate for

Table 1. Comparison results of tensile secant stiffness.

\begin{tabular}{|c|c|c|c|c|}
\hline Specimen & \multicolumn{4}{|c|}{ Tensile stiffness $(\mathrm{kN} / \mathrm{mm})$} \\
\hline \multirow{3}{*}{ A-S-1-12 } & $K_{1.2 \mathrm{R}}$ & 6.78 & $K_{2,4 \mathrm{R}}$ & 5.71 \\
\hline & $K_{1.2 \mathrm{~F}}$ & 10.21 & $K_{2.4 \mathrm{~F}}$ & 6.94 \\
\hline & $K_{1.2 \mathrm{~F}} / K_{1.2 \mathrm{R}}$ & 1.50 & $K_{2.4 F} / K_{2.4 R}$ & 1.22 \\
\hline \multirow{3}{*}{ L-S-1-12 } & $K_{1.2 \mathrm{R}}$ & 7.03 & $K_{2.4 \mathrm{R}}$ & 6.94 \\
\hline & $K_{1.2 \mathrm{~F}}$ & 13.87 & $K_{2,4 \mathrm{~F}}$ & 9.37 \\
\hline & $K_{1.2 \mathrm{~F}} / K_{1.2 \mathrm{R}}$ & 1.97 & $K_{2.4 \mathrm{~F}} / K_{2.4 \mathrm{R}}$ & 1.35 \\
\hline \multirow{3}{*}{ A-S-2pa-8 } & $K_{1.2 \mathrm{R}}$ & 10.69 & $K_{2.4 \mathrm{R}}$ & 8.51 \\
\hline & $K_{1.2 \mathrm{~F}}$ & 15.98 & $K_{2,4 \mathrm{~F}}$ & 10.76 \\
\hline & $K_{1.2 \mathrm{~F}} / K_{1.2 \mathrm{R}}$ & 1.49 & $K_{2.4 \mathrm{~F}} / K_{2.4 \mathrm{R}}$ & 1.26 \\
\hline \multirow{3}{*}{ L-S-2pa-8 } & $K_{1.2 \mathrm{R}}$ & 12.52 & $K_{2,4 R}$ & 11.30 \\
\hline & $K_{1.2 \mathrm{~F}}$ & 21.04 & $K_{2,4 \mathrm{~F}}$ & 14.23 \\
\hline & $K_{1.2 \mathrm{~F}} / K_{1.2 \mathrm{R}}$ & 1.68 & $K_{2.4 \mathrm{~F}} / K_{2.4 \mathrm{R}}$ & 1.26 \\
\hline \multirow{3}{*}{ A-S-4-6 } & $K_{0.6 \mathrm{R}}$ & 25.13 & $K_{1.2 \mathrm{R}}$ & 18.66 \\
\hline & $K_{0.6 \mathrm{~F}}$ & 32.13 & $K_{1.2 \mathrm{~F}}$ & 22.77 \\
\hline & $K_{0.6 \mathrm{~F}} / K_{0.6 \mathrm{R}}$ & 1.28 & $K_{1.2 \mathrm{~F}} / K_{1.2 \mathrm{R}}$ & 1.22 \\
\hline \multirow{3}{*}{ L-S-4-6 } & $K_{0.6 \mathrm{R}}$ & 22.70 & $K_{1.2 \mathrm{R}}$ & 21.09 \\
\hline & $K_{0.6 \mathrm{~F}}$ & 39.43 & $K_{1.2 \mathrm{~F}}$ & 30.68 \\
\hline & $K_{0.6 \mathrm{~F}} / K_{0.6 \mathrm{R}}$ & 1.74 & $K_{1.2 \mathrm{~F}} / K_{1.2 \mathrm{R}}$ & 1.45 \\
\hline \multirow{3}{*}{$\mathrm{SC} 2-3$} & $K_{0.2 \mathrm{R}}$ & 296.8 & $K_{0.4 \mathrm{R}}$ & 177.2 \\
\hline & $K_{0.2 \mathrm{~F}}$ & 243.9 & $K_{0.4 \mathrm{~F}}$ & 152.0 \\
\hline & $K_{0.2 \mathrm{~F}} / K_{0.2 \mathrm{R}}$ & 0.82 & $K_{0.4 \mathrm{~F}} / K_{0.4 \mathrm{R}}$ & 0.86 \\
\hline \multirow{3}{*}{ SC2-4 } & $K_{0.2 \mathrm{R}}$ & 344.8 & $K_{0.4 \mathrm{R}}$ & 203.6 \\
\hline & $K_{0.2 \mathrm{~F}}$ & 280.0 & $K_{0.4 \mathrm{~F}}$ & 180.8 \\
\hline & $K_{0.2 \mathrm{~F}} / K_{0.2 \mathrm{R}}$ & 0.81 & $K_{0.4 \mathrm{~F}} / K_{0.4 \mathrm{R}}$ & 0.89 \\
\hline
\end{tabular}


evaluating the effectiveness of diagonal bracing members in cold-formed structure, and this treatment can overestimate the stability of the whole thin-walled structure.

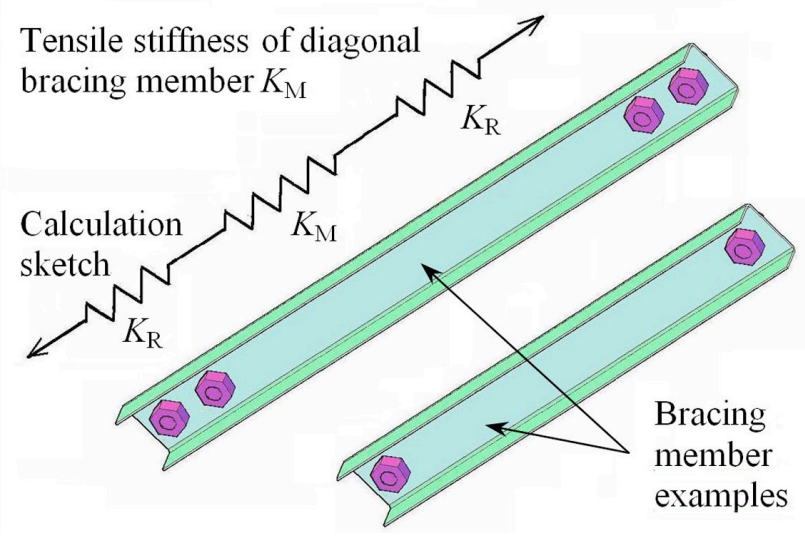

Fig. (8). Stiffness analysis of diagonal bracing system.

\section{PARAMETRIC ANALYSIS}

\subsection{Description of FE Model}

In order to achieve a comprehensive understanding of the tensile stiffness of cold-formed steel bolted connection, an extensive parametric study with the similar FE analysis procedure mentioned before was conducted.

The configuration of bolted connections is shown in Fig. (9). The FE models only contain the single shear bolted connection with one bolt or two bolts. As shown in Fig. (9), the main geometric parameters are considered as follows:

(1) end distance $\left(e_{1}\right)$ from the center of a bolt hole to the adjacent end in the direction of load transfer is three times that of the diameter $\left(d_{0}\right)$ of bolt holes;

(2) longitudinal spacing $(p)$ between the centers of two bolt holes is three times that of the diameter $\left(d_{0}\right)$ of bolt holes;

(3) edge distance $\left(e_{2}\right)$ from the center of a bolt hole to the adjacent side edge is two and a half times that of the diameter $\left(d_{0}\right)$ of bolt holes;

(4) the length from the center of bolt connection to the loading end of steel plate is assigned to be $100 \mathrm{~mm}$;

(5) plate thickness $(t), 1.5 \mathrm{~mm}, 2.0 \mathrm{~mm}, 2.5 \mathrm{~mm}$ and $3.0 \mathrm{~mm}$;

(6) yield strength $\left(f_{\mathrm{y}}\right)$ of steel plate, $300 \mathrm{MPa}, 375 \mathrm{MPa}$ and $450 \mathrm{MPa}$;

(7) bolt diameters $(d), 6 \mathrm{~mm}, 8 \mathrm{~mm}, 10 \mathrm{~mm}$ and $12 \mathrm{~mm}$;

(8) bolt hole diameter $\left(d_{0}\right)$ is $1 \mathrm{~mm}$ larger than the bolt diameter $(d)$ if $d$ is smaller than $12 \mathrm{~mm}$, otherwise the $d_{0}$ is $2 \mathrm{~mm}$ larger than $d$;
(9) the diameter $\left(d_{y}\right)$ of influential area (similar to area 1 in Fig. 6) owing to the restraining effect of bolt head is 2 mm larger than $d_{0}$ when $d$ is $6 \mathrm{~mm}$, and the $d_{\mathrm{y}}$ is $2.5 \mathrm{~mm}$ larger than $d_{0}$ when $d$ is $8 \mathrm{~mm}$ or $10 \mathrm{~mm}$, and the $d_{\mathrm{y}}$ is 3.0 $\mathrm{mm}$ larger than $d_{0}$ when $d$ is $12 \mathrm{~mm}$.

The spacing requirements in the bolted connection as specified in the different specifications [1-3] are presented in Table 2. The spacing in the bolted connections for the parametric analysis satisfies the minimum requirements of the different specifications.

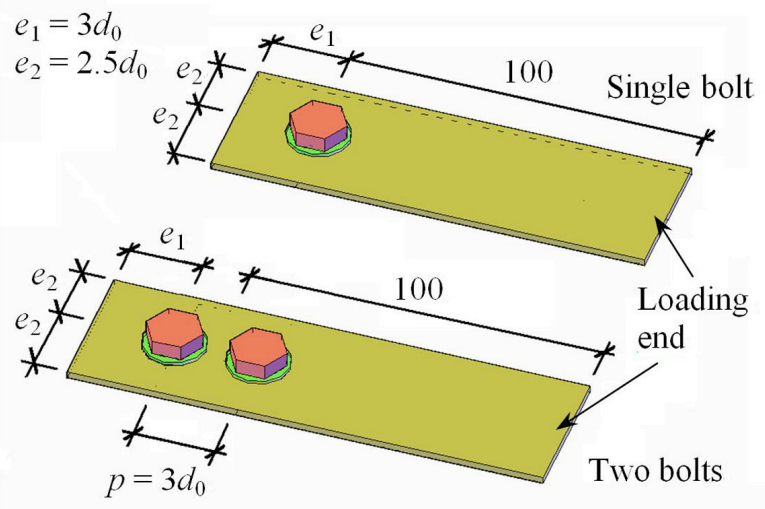

Fig. (9). Configuration of connections in parametric analysis.

Fig. (10) illustrates the FE models of bolted connections in parametric analysis. The procedures and details of numerical simulation are similar to that of FE modeling mentioned in the above section. The only one difference is that the nodes in side edges of FE models are fixed in the plate thickness direction $\left(u_{2}=0\right)$. This treatment is to consider the constraint effect of two flanges of $\mathrm{C}$ section members which are used frequently as the diagonal bracing members in cold-formed structure.

One important aspect that has been neglected in the parametric analysis is the frictional forces between the plates, which are related to the clamping force in the bolt. There are a lot of varieties for the cold-formed structure. For the different varieties of cold-formed structure, the installation and application requirements are different, thus there is a great difference in the clamping force of the bolt. For this reason, the FE analyses in the section do not consider the frictional force between plates and the pretension force in the bolt.

A total of 96 specimens were planned and the tensile stiffness of connection specimens is listed in Table 3. Each specimen has three secant stiffnesses $\left(K_{0.25}, K_{0.5}\right.$ and $\left.K_{1.0}\right)$, and in other words, the displacements of selected points for the secant lines are $0.25 \mathrm{~mm}, 0.5 \mathrm{~mm}$ and $1.0 \mathrm{~mm}$.

Table 2. Spacing requirements in different specifications.

\begin{tabular}{|c|c|c|c|}
\hline Specification & End distance $\left(\boldsymbol{e}_{\mathbf{1}}\right)$ & Edge distance $\left(\boldsymbol{e}_{\mathbf{2}}\right)$ & Longitudinal spacing $(\boldsymbol{p})$ \\
\hline \hline GB 50018 & $\geq 2.0 d_{0}$ & $\geq 1.5 d_{0}$ & $\geq 3.0 d_{0}$ \\
\hline AISI & $\geq 1.5 d$ & $\geq 1.5 d$ & $\geq 3.0 d$ \\
\hline AS/NZS & $\geq 1.5 d$ & $\geq 1.5 d$ & $\geq 3.0 d$ \\
\hline
\end{tabular}




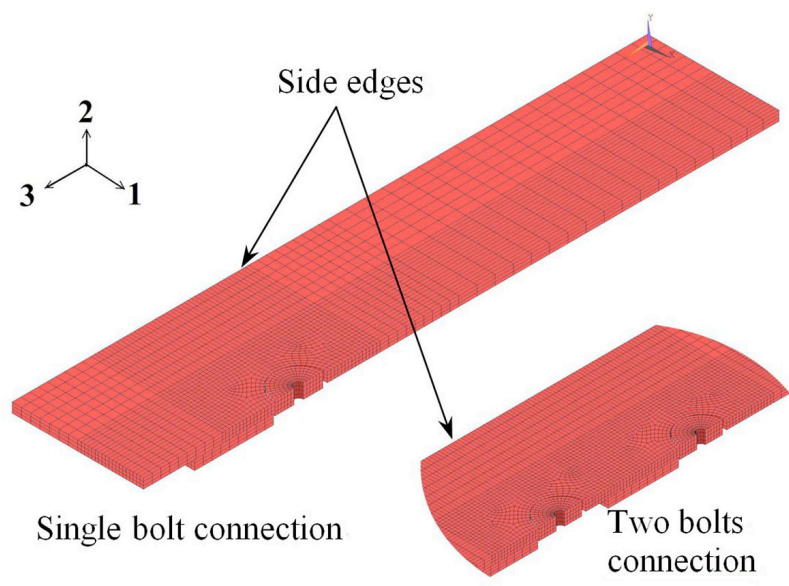

Fig. (10). FE models of connections in parametric analysis.

Each connection specimen is labeled by four segments in order to identify the number of bolts, bolt size, plate thickness and steel yield strength. For example, the specimen labels "S-6-1.5-300" and "T-12-2.5-450" define the following specimens:

The first letter indicates the number of bolts in the connection, where " $\mathrm{S}$ " represents that there is single bolt in the specimen and " $\mathrm{T}$ " represents that there are two bolts in the specimen.

The second part of the label indicates the diameter of bolts used in the connection. The number " 6 " means that the bolt diameter is $6 \mathrm{~mm}$, while " 12 " stands for $12 \mathrm{~mm}$.

The third letter indicates the thickness of steel plate in the connection. The number " 1.5 " represents that the plate thickness is $1.5 \mathrm{~mm}$, while " 2.5 " stands for $2.5 \mathrm{~mm}$.

The fourth part of the labels means the yield strength of steel plate, where " 300 " and " 450 " represent $300 \mathrm{MPa}$ and $450 \mathrm{MPa}$ respectively.

\subsection{Influence of Plate Thickness $(t)$}

For one set of specimens with different plate thickness and with the same bolt diameter and steel yield strength, the influences of plate thickness on load-displacement relationships and plate deformation are shown in Fig. (11) and Fig. (12) respectively. In Fig. (11), when the steel plate thickness is small, the load that is resisted by connection increases with the growth of connection displacement slowly, and the load shows the downward trend after reaching the large displacement. The global displacements of steel plate in Fig. (12) are the same, but there is a great difference in the degree of curling deformation of steel plates with different plate thicknesses. From the foregoing discussion, it can be seen that the curling deformation has a negative effect on the growth of the load [9]. The more seriously the curling deforms, the less quickly the load grows.

For the four sets of connection specimens with the different plate thickness and with the same bolt diameter and steel yield strength, the influence of plate thickness on tensile stiffness is shown in Fig. (13). The tensile stiffness of bolted connection grows linearly as the plate thickness increases.

\subsection{Influence of Bolt Diameter $(d)$ and Steel Strength $\left(f_{y}\right)$}

For the four sets of connection specimens with the different bolt diameters and with the same plate thickness and steel yield strength, the influence of bolt diameter on tensile stiffness is shown in Fig. (14a). For the relationship of bolt diameter and connection tensile stiffness, the linear relationship is approximately existent when the bolt diameter $d$ is between $6 \mathrm{~mm}$ and $10 \mathrm{~mm}$. There are turn points in the relationship curves in Fig. (14a), when $d$ is larger than 10 $\mathrm{mm}$.

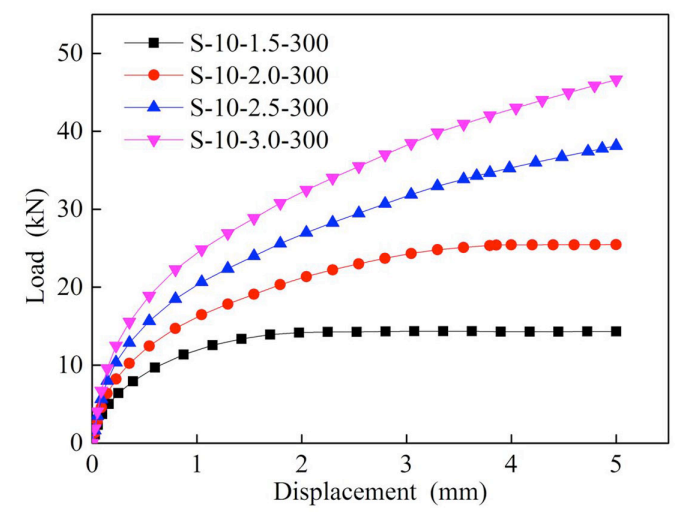

Fig. (11). Influence of plate thickness on load-displacement relationships.
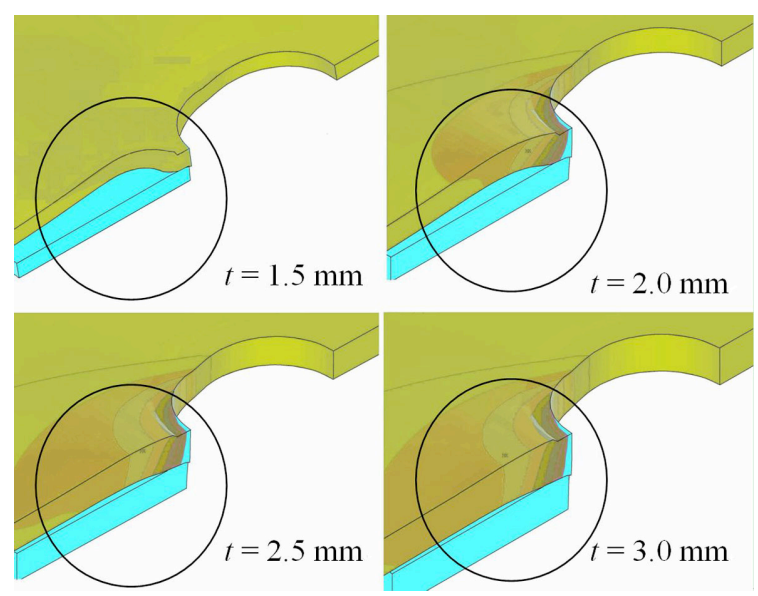

Fig. (12). Influence of plate thickness on plate deformation.

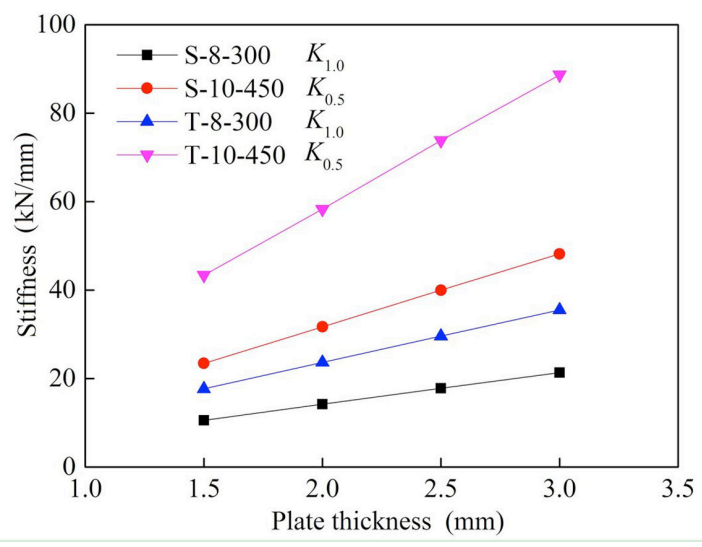

Fig. (13). Influence of plate thickness on tensile stiffness. 
Table 3. Tensile stiffness of bolted connections in parametric analysis.

\begin{tabular}{|c|c|c|c|c|c|c|c|c|c|c|c|}
\hline \multirow{2}{*}{ Connections } & \multicolumn{3}{|c|}{ Tensile stiffness (kN/mm) } & \multirow{2}{*}{ Connections } & \multicolumn{3}{|c|}{ Tensile stiffness (kN/mm) } & \multirow{2}{*}{ Connections } & \multicolumn{3}{|c|}{ Tensile stiffness $(\mathrm{kN} / \mathrm{mm})$} \\
\hline & $K_{0.25}$ & $K_{0.5}$ & $K_{1.0}$ & & $K_{0.25}$ & $K_{0.5}$ & $K_{1.0}$ & & $K_{0.25}$ & $K_{0.5}$ & $K_{1.0}$ \\
\hline S-6-1.5-300 & 17.68 & 12.9 & 8.81 & S-6-1.5-375 & 20.32 & 14.82 & 10.11 & S-6-1.5-450 & 23.2 & 16.7 & 11.35 \\
\hline S-6-2.0-300 & 24.08 & 17.32 & 11.85 & S-6-2.0-375 & 27.88 & 19.96 & 13.61 & S-6-2.0-450 & 31.36 & 22.52 & 15.27 \\
\hline S-6-2.5-300 & 29.88 & 21.7 & 14.79 & S-6-2.5-375 & 34.48 & 25.12 & 16.98 & S-6-2.5-450 & 38.84 & 28.34 & 19.12 \\
\hline S-6-3.0-300 & 35.96 & 26.14 & 17.69 & S-6-3.0-375 & 41.36 & 30.22 & 20.37 & S-6-3.0-450 & 46.28 & 34.08 & 22.9 \\
\hline S-8-1.5-300 & 22.24 & 15.52 & 10.57 & S-8-1.5-375 & 25.76 & 18.02 & 12.19 & S-8-1.5-450 & 29.12 & 20.38 & 13.73 \\
\hline S-8-2.0-300 & 29.68 & 21.02 & 14.2 & S-8-2.0-375 & 34.36 & 24.42 & 16.42 & S-8-2.0-450 & 39.16 & 27.66 & 18.54 \\
\hline S-8-2.5-300 & 37.32 & 26.5 & 17.78 & S-8-2.5-375 & 43.12 & 30.66 & 20.61 & S-8-2.5-450 & 48.92 & 34.86 & 23.22 \\
\hline S-8-3.0-300 & 44.84 & 31.86 & 21.35 & S-8-3.0-375 & 52.08 & 37.02 & 24.75 & S-8-3.0-450 & 58.8 & 41.94 & 27.95 \\
\hline S-10-1.5-300 & 25.72 & 17.72 & 11.93 & S-10-1.5-375 & 29.88 & 20.68 & 13.77 & S-10-1.5-450 & 33.32 & 23.44 & 15.59 \\
\hline S-10-2.0-300 & 34.36 & 23.96 & 16.19 & S-10-2.0-375 & 40.08 & 27.78 & 18.72 & S-10-2.0-450 & 45.28 & 31.68 & 21.06 \\
\hline S-10-2.5-300 & 43.32 & 30.02 & 20.29 & S-10-2.5-375 & 50.2 & 35.12 & 23.49 & S-10-2.5-450 & 56.64 & 39.98 & 26.52 \\
\hline S-10-3.0-300 & 52.24 & 36.16 & 24.38 & S-10-3.0-375 & 60.68 & 42.38 & 28.27 & S-10-3.0-450 & 68.4 & 48.18 & 31.92 \\
\hline S-12-1.5-300 & 25.88 & 18.54 & 12.97 & S-12-1.5-375 & 30.08 & 21.52 & 14.99 & S-12-1.5-450 & 34.28 & 24.5 & 16.97 \\
\hline S-12-2.0-300 & 34.64 & 24.98 & 17.44 & S-12-2.0-375 & 40.56 & 28.88 & 20.19 & S-12-2.0-450 & 46.12 & 32.92 & 22.86 \\
\hline S-12-2.5-300 & 43.44 & 31.38 & 21.92 & S-12-2.5-375 & 51.2 & 36.42 & 25.33 & S-12-2.5-450 & 57.88 & 41.52 & 28.58 \\
\hline S-12-3.0-300 & 52.76 & 37.64 & 26.38 & S-12-3.0-375 & 61.72 & 44.16 & 30.6 & S-12-3.0-450 & 70.08 & 50.14 & 34.63 \\
\hline T-6-1.5-300 & 32.12 & 23.38 & 14.27 & T-6-1.5-375 & 36.52 & 27.1 & 17.05 & $\mathrm{~T}-6-1.5-450$ & 40.44 & 30.38 & 19.74 \\
\hline T-6-2.0-300 & 43.52 & 31.48 & 19.09 & T-6-2.0-375 & 49.64 & 36.52 & 22.81 & $\mathrm{~T}-6-2.0-450$ & 55.12 & 41.12 & 26.43 \\
\hline T-6-2.5-300 & 54.48 & 39.66 & 23.87 & $\mathrm{~T}-6-2.5-375$ & 62.64 & 46.08 & 28.54 & $\mathrm{~T}-6-2.5-450$ & 69.88 & 51.84 & 33.07 \\
\hline T-6-3.0-300 & 66.12 & 47.18 & 28.69 & $\mathrm{~T}-6-3.0-375$ & 74.92 & 55.28 & 34.29 & $\mathrm{~T}-6-3.0-450$ & 83.08 & 62.16 & 39.72 \\
\hline T-8-1.5-300 & 39.84 & 28.68 & 17.66 & $\mathrm{~T}-8-1.5-375$ & 45.96 & 33.3 & 21.24 & $\mathrm{~T}-8-1.5-450$ & 51.52 & 37.4 & 24.55 \\
\hline T-8-2.0-300 & 54.12 & 38.44 & 23.66 & T-8-2.0-375 & 62.28 & 44.82 & 28.38 & $\mathrm{~T}-8-2.0-450$ & 69.68 & 50.68 & 32.74 \\
\hline $\mathrm{T}-8-2.5-300$ & 68.64 & 48.38 & 29.59 & $\mathrm{~T}-8-2.5-375$ & 78.88 & 56.4 & 35.5 & $\mathrm{~T}-8-2.5-450$ & 88.36 & 63.7 & 41.07 \\
\hline T-8-3.0-300 & 82.52 & 58.24 & 35.51 & $\mathrm{~T}-8-3.0-375$ & 94.96 & 68.08 & 42.63 & $\mathrm{~T}-8-3.0-450$ & 105.2 & 76.86 & 49.2 \\
\hline $\mathrm{T}-10-1.5-300$ & 46.28 & 33.1 & 20.88 & $\mathrm{~T}-10-1.5-375$ & 53.6 & 38.24 & 25.01 & $\mathrm{~T}-10-1.5-450$ & 59.96 & 43.36 & 28.71 \\
\hline $\mathrm{T}-10-2.0-300$ & 62.44 & 44.22 & 27.93 & $\mathrm{~T}-10-2.0-375$ & 72.48 & 51.46 & 33.41 & $\mathrm{~T}-10-2.0-450$ & 81.04 & 58.28 & 38.52 \\
\hline $\mathrm{T}-10-2.5-300$ & 79.01 & 55.9 & 34.96 & $\mathrm{~T}-10-2.5-375$ & 91.2 & 64.9 & 41.73 & $\mathrm{~T}-10-2.5-450$ & 102.6 & 73.82 & 48.06 \\
\hline $\mathrm{T}-10-3.0-300$ & 95.56 & 67.22 & 41.94 & $\mathrm{~T}-10-3.0-375$ & 110.04 & 78.38 & 50.24 & $\mathrm{~T}-10-3.0-450$ & 122.64 & 88.66 & 57.88 \\
\hline $\mathrm{T}-12-1.5-300$ & 48.04 & 34.92 & 24.21 & $\mathrm{~T}-12-1.5-375$ & 55.92 & 40.8 & 28.41 & $\mathrm{~T}-12-1.5-450$ & 62.84 & 46.1 & 32.16 \\
\hline $\mathrm{T}-12-2.0-300$ & 65.4 & 47.02 & 32.49 & $\mathrm{~T}-12-2.0-375$ & 75.68 & 54.84 & 38.03 & $\mathrm{~T}-12-2.0-450$ & 84.36 & 62.12 & 43.11 \\
\hline $\mathrm{T}-12-2.5-300$ & 82.76 & 59.5 & 40.52 & $\mathrm{~T}-12-2.5-375$ & 94.6 & 69.14 & 47.6 & $\mathrm{~T}-12-2.5-450$ & 106.72 & 78.38 & 54.16 \\
\hline $\mathrm{T}-12-3.0-300$ & 99.56 & 71.56 & 48.65 & $\mathrm{~T}-12-3.0-375$ & 114.24 & 83.62 & 57.31 & $\mathrm{~T}-12-3.0-450$ & 127.88 & 94.36 & 65.11 \\
\hline
\end{tabular}




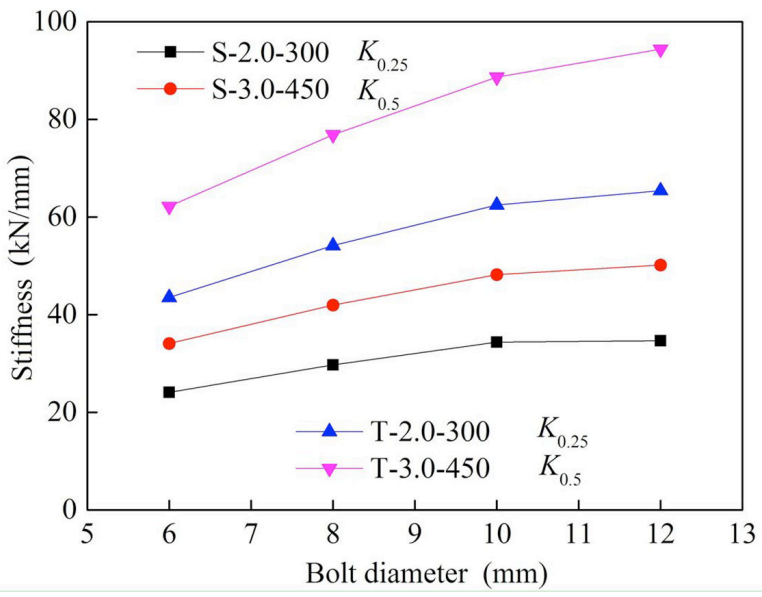

(a) Bolt diameter

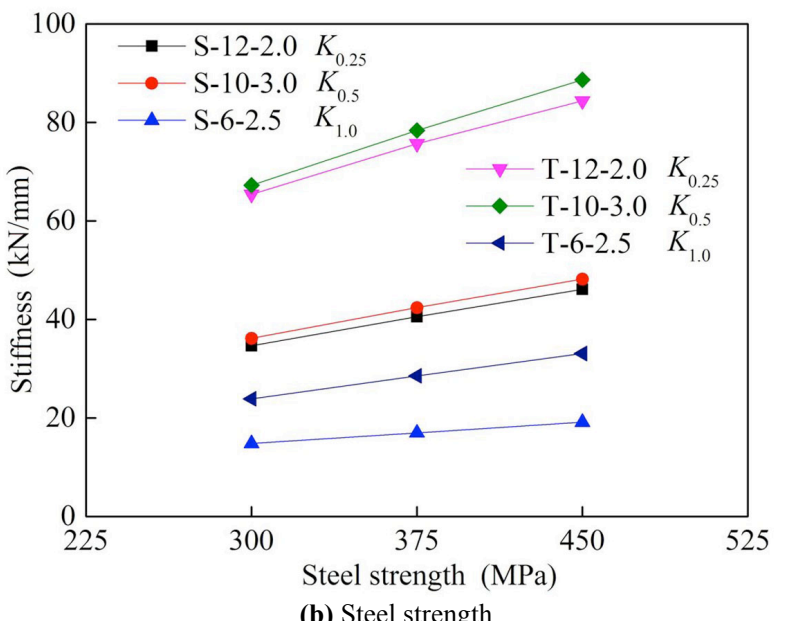

(b) Steel strength

Fig. (14). Influence of structural parameters on tensile stiffness.

For the six sets of specimens with the different steel yield strengths and with the same plate thickness and bolt diameter, the influence of steel strength on connection tensile stiffness is shown in Fig. (14b). Like the plate thickness, the steel strength also has the linear relationship with tensile stiffness of bolted connection. The tensile stiffness increases linearly with the growth of steel strength.

\subsection{Influence of End Distance $\left(e_{1}\right)$ and Edge Distance $\left(e_{2}\right)$}

As shown in Fig. (9), the end distance $e_{1}$ and edge distance $e_{2}$ are regarded as changeless values in parametric study discussed before, $e_{1}=3 d_{0}$ and $e_{2}=2.5 d_{0}$. In order to study the effects of $e_{1}$ and $e_{2}$ on tensile stiffness, two series of bolted connections with different values of $e_{1}$ and $e_{2}$ are calculated in this section on the condition of satisfying all the design constraints in Table 2. For end distance $e_{1}$, there are three values: $2 d_{0}, 3 d_{0}$ and $4 d_{0}$. For edge distance $e_{2}$, there are three values: $1.5 d_{0}, 2.5 d_{0}$ and $3.5 d_{0}$. The values of $2 d_{0}$ and $1.5 d_{0}$ are the minimum distances of $e_{1}$ and $e_{2}$ in design specification [1], respectively. The two series of connection models are based on the aforementioned connection models S-6-1.5-300 and S-12-3.0-300 by varying the values of $e_{1}$ and $e_{2}$.

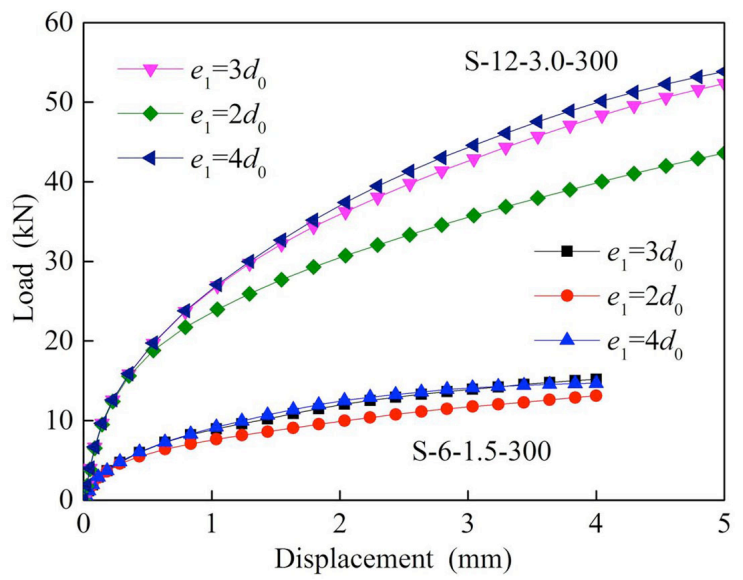

(a) $e_{1}$

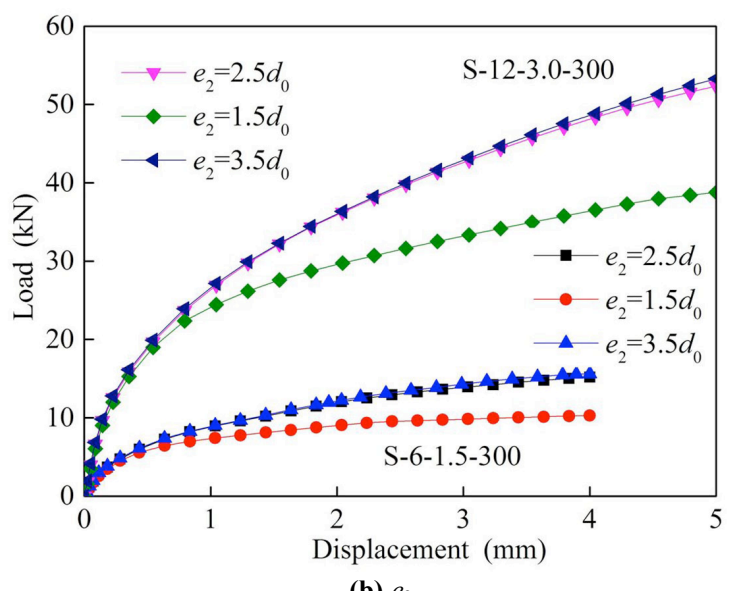

Fig. (15). Influence of $e_{1}$ and $e_{2}$ on load-displacement relationships.

The influences of end distance $e_{1}$ and edge distance $e_{2}$ on load-displacement relationships are shown in Fig. (15). The influences of $e_{1}$ and $e_{2}$ on tensile stiffness are listed in Table 4 and Table 5 respectively. Both the change of $e_{1}$ from $2 d_{0}$ to $3 d_{0}$ and the change of $e_{2}$ from $1.5 d_{0}$ to $2.5 d_{0}$ have a large effect on load-displacement relationships and tensile stiffness. The differences between load-displacement curves become large with the growth of the displacement. In addition, the changes of $e_{1}$ from $2 d_{0}$ to $3 d_{0}$ and $e_{2}$ from $1.5 d_{0}$ to $2.5 d_{0}$ have larger influence on the secant stiffness $K_{1.0}$ than the secant stiffnesses $K_{0.5}$ and $K_{0.25}$. However, the sustained growths of $e_{1}$ from $3 d_{0}$ to $4 d_{0}$ and $e_{2}$ from $2.5 d_{0}$ to $3.5 d_{0}$ do not have much impact on load-displacement relationships and tensile stiffness.

Fig. (16) shows the influences of $e_{1}$ and $e_{2}$ on plate deformation of bolted connections. The steel plate global displacements of three connection models in Fig. (16) are the same. The connection model with a relative small value of $e_{1}$ has a large shear deformation in the end region, and the connection model with a relative small value of $e_{2}$ has a large necking deformation in the net section.

\section{CALCULATING EQUATIONS FOR TENSILE STIFFNESS}

As mentioned before, the relationship of tensile stiffness of bolt connection and the bolt diameter which is between 6 
Table 4. Influence of $e_{1}$ on tensile stiffness.

\begin{tabular}{|c|c|c|c|c|c|}
\hline \multicolumn{6}{|c|}{ Specimen S-6-1.5-300 } \\
\hline$K_{0.5}$ & 12.9 & 11.58 & 0.898 & 12.98 & 1.006 \\
\hline$K_{1.0}$ & 8.81 & 7.58 & 0.860 & 9.04 & 1.026 \\
\hline & $e_{1}=3 d_{0} K_{(3)}$ & $e_{1}=2 d_{0} K_{(2)}$ & $\boldsymbol{K}_{(2)} / \boldsymbol{K}_{(3)}$ & $e_{1}=4 d_{0} \quad K_{(4)}$ & $\boldsymbol{K}_{(\mathbf{4})} / \boldsymbol{K}_{(\mathbf{3 )}}$ \\
\hline$K_{0.25}$ & 52.76 & 51.96 & 0.985 & 52.82 & 1.001 \\
\hline$K_{0.5}$ & 37.65 & 36.24 & 0.963 & 37.74 & 1.003 \\
\hline
\end{tabular}

Table 5. Influence of $e_{2}$ on tensile stiffness.

\begin{tabular}{|c|c|c|c|c|c|}
\hline \multicolumn{6}{|c|}{ Specimen S-6-1.5-300 } \\
\hline$K_{0.5}$ & 12.9 & 11.70 & 0.907 & 12.99 & 1.007 \\
\hline$K_{1.0}$ & 8.81 & 7.26 & 0.824 & 8.88 & 1.008 \\
\hline \multicolumn{6}{|c|}{ Specimen S-12-3.0-300 } \\
\hline & $e_{2}=2.5 d_{0} K_{(2.5)}$ & $e_{2}=1.5 d_{0} K_{(1.5)}$ & $K_{(1.5)} / K_{(2.5)}$ & $e_{2}=3.5 d_{0} K_{(3.5)}$ & $\boldsymbol{K}_{(3.5)} / \boldsymbol{K}_{(2.5)}$ \\
\hline$K_{0.25}$ & 52.76 & 50.97 & 0.966 & 53.36 & 1.011 \\
\hline$K_{0.5}$ & 37.64 & 36.22 & 0.962 & 38.10 & 1.012 \\
\hline
\end{tabular}

$\mathrm{mm}$ and $10 \mathrm{~mm}$ is approximately linear. Therefore, when the bolt diameter is between $6 \mathrm{~mm}$ and $10 \mathrm{~mm}$, the bolt diameter is a linear factor of the connection stiffness, just as the other two parameters (plate thickness and steel yield strength). Multiple linear regression analysis was used to reveal the influence of three parameters (bolt diameter, plate thickness and steel yield strength) on the bolt connection, and the Eqs. (1) to (6) are proposed.

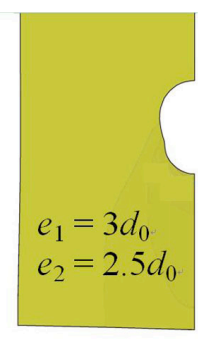

Large shear deformation

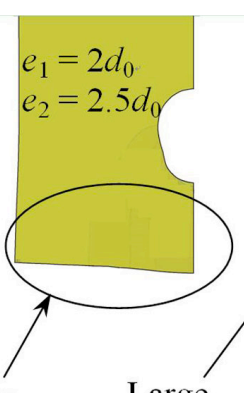

Large necking deformation

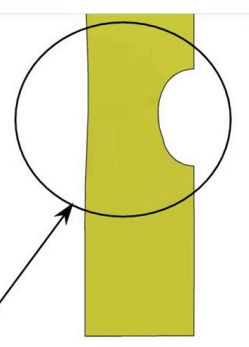

$e_{1}=3 d_{0}$ $e_{2}=1.5 d_{0}$
Fig. (16). Influences of $e_{1}$ and $e_{2}$ on plate deformation.
For the single bolt connection and the bolt diameter between 6 and $10 \mathrm{~mm}$, the secant stiffness $K_{0.25}$ is calculated as:

$K_{0.25}=3.53 \times d+17.26 \times t+0.068 \times f_{\mathrm{y}}-54.13$

The secant stiffness $K_{0.5}$ is calculated as:

$K_{0.5}=2.26 \times d+12.45 \times t+0.049 \times f_{\mathrm{y}}-37.25$

The secant stiffness $K_{1.0}$ is calculated as:

$K_{1.0}=1.44 \times d+8.26 \times t+0.032 \times f_{\mathrm{y}}-23.84$

For the two bolts connection and the bolt diameter between 6 and $10 \mathrm{~mm}$, the secant stiffness $K_{0.25}$ is calculated as:

$K_{0.25}=6.43 \times d+31.82 \times t+0.115 \times f_{\mathrm{y}}-96.45$

The secant stiffness $K_{0.5}$ is calculated as:

$K_{0.5}=4.28 \times d+22.77 \times t+0.091 \times f_{\mathrm{y}}-69.45$

The secant stiffness $K_{1.0}$ is calculated as:

$K_{1.0}=2.98 \times d+14.15 \times t+0.068 \times f_{\mathrm{y}}-49.15$

The ratio between tensile stiffness of bolted connection with $12 \mathrm{~mm}$ bolt diameter and that of bolted connection with 
Table 6. Values of parameter $\mu$.

\begin{tabular}{|c|c|c|c|c|c|c|}
\hline \multirow{2}{*}{ Parameter } & \multicolumn{3}{|c|}{ Single bolt connection } & \multicolumn{3}{c|}{ Two bolts connection } \\
\cline { 2 - 7 } & $\boldsymbol{K}_{\mathbf{0 . 2 5}}$ & $\boldsymbol{K}_{\mathbf{0 . 5}}$ & $\boldsymbol{K}_{\mathbf{1 . 0}}$ & $\boldsymbol{K}_{\mathbf{0 . 2 5}}$ & $\boldsymbol{K}_{\mathbf{0 . 5}}$ & $\boldsymbol{K}_{\mathbf{1 . 0}}$ \\
\hline \hline$\mu$ & 1.00 & 1.04 & 1.07 & 1.03 & 1.05 \\
\hline
\end{tabular}

$10 \mathrm{~mm}$ bolt diameter is referred to as the parameter $\mu$. The values of parameter $\mu$ are listed in Table 6 . The tensile stiffness of bolted connection with $10 \mathrm{~mm}$ bolt diameter can be calculated from the Eqs. (1) to (6). After using the parameter $\mu$, the tensile stiffness of connection with $12 \mathrm{~mm}$ bolt diameter can also be obtained. The linear interpolation method can be used to calculate the tensile stiffness of connection whose bolt diameter ranges from $10 \mathrm{~mm}$ to 12 $\mathrm{mm}$.

A plot of the tensile stiffness based on the proposed calculation equations against that from $\mathrm{FE}$ models of specimens (Table 3) is presented in Fig. (17). It is shown that the proposed calculation equations are accurate over the entire range of connection configurations covered in the parametric study.

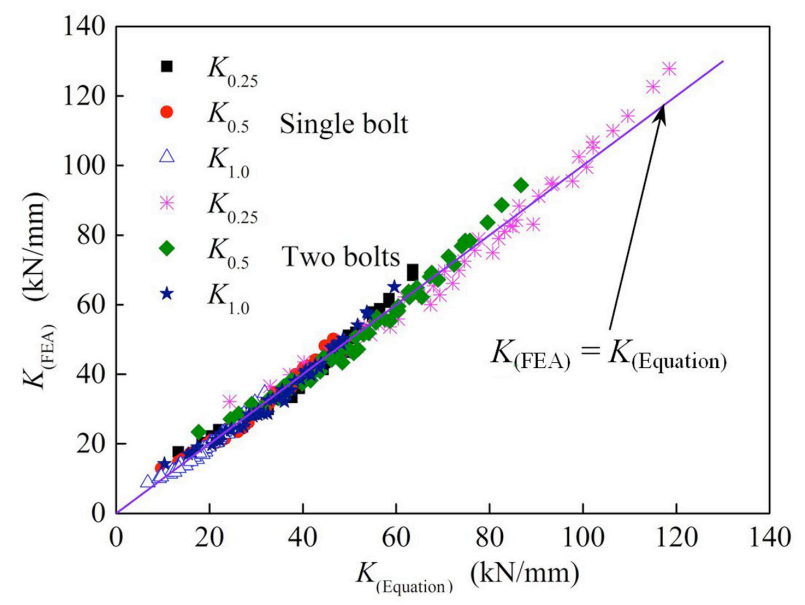

Fig. (17). Comparison of tensile stiffness between proposed equations and finite element analysis.

\section{CONCLUSION}

This paper mainly discussed the tensile stiffness of bolted connections with thin-walled cold-formed steel strips, and the research mainly adopted the finite element numerical analysis method which is compared with existing experimental results and analytical results.

The finite element modeling of single shear bolted connections with cold-formed steel plates was carried out with non-linear material and contact elements. The loaddisplacement relationships of eight specimens in two references $[8,11]$ were chosen to calibrate the finite element models. The FE models were established with bilinear stressstrain curves and without strength degradation. For purpose of simple computation, only a half of one strip was modeled, and the extension deformation of the FE model was one half of that of the actual bolted connection which contains two same cold-formed steel plates. Since most of the bolted connections with cold-formed steel are the bearing type connection and not the frictional type connection, and the clamping force of bolt cannot be simultaneously maintained for a long period of time, the bolt pre-tension was not simulated. The thickness direction displacement in the vicinity of bolt hole was set to be fixed by constraining the associated node to account for the restraining effect of the bolt head. As the influence of various defects was ignored such as bolt thread, rough edge of steel strip and small machining gap between bolt bar and bolt hole, and the strength degradation of steel at large strain, the secant stiffness of load-displacement curves from finite element analysis during the initiation of loading was larger than that of the experimental curves. The appearance of out-of plane curling deformation at the later loading stage can lead to strength reduction of bolted connection [9].

According to single-bolted and two-bolted connections, a total of 96 FE models for additional parametric study regarding bolted connections with extended variables (bolt diameter, plate thickness and yield strength) were analyzed. Based on the results of parametric study, six calculation equations of tensile stiffness for bolted connection were proposed in this paper and were applicable for the following variables: plate thickness ranging from $1.5 \mathrm{~mm}$ to $3.0 \mathrm{~mm}$, bolt diameter ranging from $6 \mathrm{~mm}$ to $12 \mathrm{~mm}$, steel yield strength ranging from $300 \mathrm{~N} / \mathrm{mm}^{2}$ to $450 \mathrm{~N} / \mathrm{mm}^{2}$, end distance $e_{1}$ and pitch of $3 d_{0}$, edge distance $e_{2}$ of $2.5 d_{0}$. The validation of proposed design equations in predicting the tensile stiffness was verified through the comparison between calculated results and $\mathrm{FE}$ analysis results.

Since the parametric research of this paper is limited to single shear bolted connections with one bolt and two bolts, therefore in future research, additional study is necessary to be carried out regarding other different parameters such as bolt arrangements, end distance, edge distance, etc. For a specific cold-formed steel structure, as the clamping force in bolt and the friction coefficient between steel plates are confirmed, the effect of these factors on tensile stiffness can be studied.

\section{ABOUT THE AUTHORS}

First Author Cheng Bo, master degree in engineering, studying for PhD in Harbin Institute of Technology of Civil Engineering. The author's major is Structural Engineering.

Second Author Wu Zhenyu, University professor of Harbin Institute of Technology, Ph.D. The author's major is light steel structure and high-rise steel structure.

\section{CONFLICT OF INTEREST}

The authors confirm that this article content has no conflict of interest. 


\section{REFERENCES}

[1] GB 50018-2002. "Technical Code of Cold-Formed Thin-Wall Steel Structures", PRC National Standard, 2002.

[2] AISI. "North American Specification for the Design of ColdFormed Steel Structural Members 2007 Edition", American Iron and Steel Institute, 2007.

[3] AS/NZS 4600-2005. "Cold-Formed Steel Structures", Standards Australia / Standards New Zealand, 2005.

[4] K. F. Chung, and K. H. Ip, "Finite element modeling of bolted connections between cold-formed steel strips and hot rolled steel plates under static shear loading", Engineering Structures, vol. 22, pp. 1271-1284, 2000.

[5] K. F. Chung, and K. H. Ip, "Finite element investigation on the structural behavior of cold-formed steel bolted connections", Engineering Structures, vol. 23, pp. 1115-1125, 2001.
[6] R. Aceti, G. Ballio, and A. Capsoni, "A limit analysis study to interpret the ultimate behavior of bolted joints", Journal of Constructional Steel Research, vol. 60, pp. 1333-1351, 2004.

[7] L. H. Teh, and V. Yazici, "Shear lag and eccentricity effects of bolted connections in cold-formed steel sections", Engineering Structures, vol. 52, pp. 536-544, 2013.

[8] T. S. Kim, and H. Kuwamura, "Finite element modeling of bolted connections in thin-walled stainless steel plates under static shear", Thin-Walled Structures, vol. 45, pp. 407-421, 2007.

[9] T. S. Kim, H. Kuwamura, and T. J. Cho, "A parametric study on ultimate strength of single shear bolted connections with curling", Thin-Walled Structures, vol. 46, pp. 38-53, 2008.

[10] E. L. Salih, L.Gardner, and D. A. Nethercot, "Bearing failure in stainless steel bolted connections", Engineering Structures, vol. 33, pp. 549-562, 2011.

[11] Y. C. Cai, and B. Young, "Structural behavior of cold-formed stainless steel bolted connections", Thin-Walled Structures, vol. 83, pp. 147-156, 2014.

Received: March 19, 2015

Revised: May 14, 2015

Accepted: May 21, 2015

(C) Cheng and Wu; Licensee Bentham Open.

This is an open access article licensed under the terms of the Creative Commons Attribution Non-Commercial License (http://creativecommons.org/licenses/ by-nc/4.0/) which permits unrestricted, non-commercial use, distribution and reproduction in any medium, provided the work is properly cited. 